\title{
Measurement of Sound Transmission Loss in a Sound Barrier Filled with the Rice-Straw Particles by the Transfer Function and Laboratory Measurement Methods ${ }^{1}$
}

\author{
Chun-Won Kang ${ }^{2} \cdot$ Eun-Suk Jang ${ }^{2} \cdot$ Sang-Sik Jang (iD ${ }^{3, \dagger} \cdot$ Ho-Yang Kang ${ }^{3}$
}

\begin{abstract}
The sound insulation capacity of a barrier is indicated by its transmission loss. In this study, the sound transmission loss of a sound barrier filled with rice-straw particles was measured by the transfer function method and a laboratory measurement method. The results of the two measurements were compared. The transmission losses measured by the two methods were similar above a frequency of $500 \mathrm{~Hz}$. The loss increased greatly upon the introduction of a plywood to the sound barrier. The results of this study are expected to be used to design sound barriers for roads.
\end{abstract}

Keywords: sound transmission loss, transfer function method, laboratory measurement methods

\section{INTRODUCTION}

Against the background of severe problems related to environmental noise, there has been a significant increase in the demand for controlling such noise. This has led to an increase in the research effort on soundproof and highly sound absorptive building materials (Kang et al., 2012). Among the sources of noise pollution, traffic noise leads to the widest range of damage and causes the most severe damage. Hence, sound barriers are built along roadsides to eliminate or reduce noise. Such sound barriers may be of the acoustic absorber type or the reactive type. Reactive sound barriers cause problems such as drivers being exposed to the reflected sound, although the walls containing using concrete panels, ceramic panels, polycarbonates, etc. provide effective soundproofing by blocking the sound transmission path from the noise source to the listeners. The sound-absorber-type barriers have an aluminum frame and fillings of porous sound-absorbing materials such as glass wool to reduce the noise.

The measurement of the sound transmission loss has been generally measured by the transfer function method and a laboratory measurement method. The transfer function method uses two transfer functions of the sound

${ }^{1}$ Date Received March 8, 2018, Date Accepted July 2, 2018

${ }^{2}$ Department of Housing Environmental Design, and Research Institute of Human Ecology, College of Human Ecology, Chonbuk National University, Jeonju 54896, Republic of Korea

${ }^{3}$ Department of Forest Products, College of Agriculture \& Life Sciences, Chungnam National University, Daejeon 34134, Republic of Korea

† Corresponding author: Sang-Sik Jang (e-mail: ssjang@cnu.ac.kr, ORCID: 0000-0002-3124-7044) 
Measurement of Sound Transmission Loss in a Sound Barrier Filled with the Rice-Straw Particles by the Transfer Function and Laboratory Measurement Methods

source part and the sound-receiving part. The transfer function method has the advantage of rapid measurement of sound transmission loss rate over a wide range of frequencies. The laboratory measurement method has the advantage of accurate measurements, but large test spaces and specimens are required for this method (Lee et al., 2011).

From the viewpoint of reuse of by-products, rice-straw particles obtained from rice straw, a by-product of rice cultivation, are commonly used in sound barriers. The use of these particles for building materials is limited by their low strength, but they can be used as a filler for acoustic-absorber-type sound barriers because their apparent density and air flow resistance can be easily controlled. In this study, the sound transmission loss of rice-straw particle mats was measured by (1) the transfer function method by using impedance tubes and (2) a laboratory measurement method to compare the two measuring methods and to evaluate the sound transmission loss of the sound barrier filled with rice-straw particles.

\section{MATERIALS and METHODS}

\subsection{Specimen preparation}

The air-dried rice straws were cut into samples 10-mm long. Impedance tubes were filled with these straws, as shown in Fig. 1. The percentage of moisture content, true density, bulk density, and the porosity of the rice straws were $7.8 \%, 0.81 \%, 0.33 \%$, and $59 \%$, respectively. The apparent specific density of the rice-straw mat on the sample holder was changed by controlling the filling pressure, and the thickness of the rice-straw mats were changed by increasing their thickness. A 10-mm-thick plywood disk was attached to the back face of the rice-straw mat to increase the transmission loss and to reinforce the strength of the mat (Fig. 1). This plywood had weight similar to that

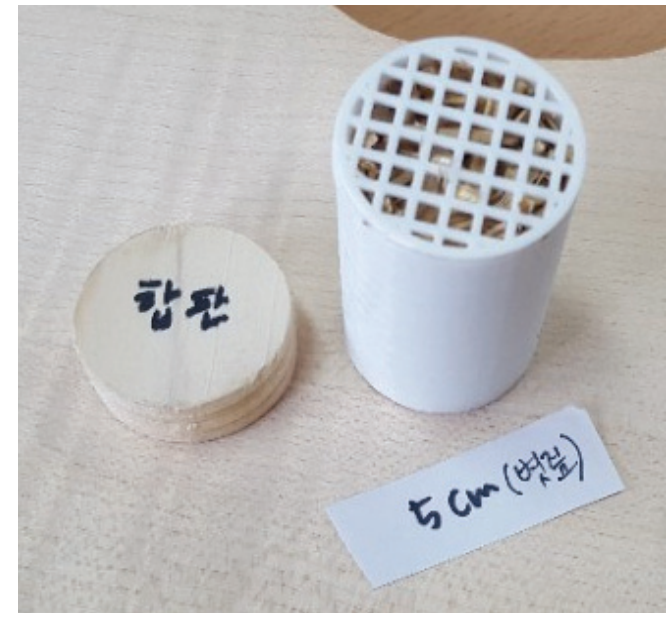

Fig. 1. Sample holder filled with rice straw.

of the metal frame used in the sound barrier.

\subsection{Measuring the acoustic transmission loss by the transfer function method}

Following ASTM E 2611-09, a specimen was placed at the center of the impedance tube, as shown in Fig. 2. In the transfer function method, an impedance tube with a sound source part and sound-receiving part was used. The sample holder was inserted between the two
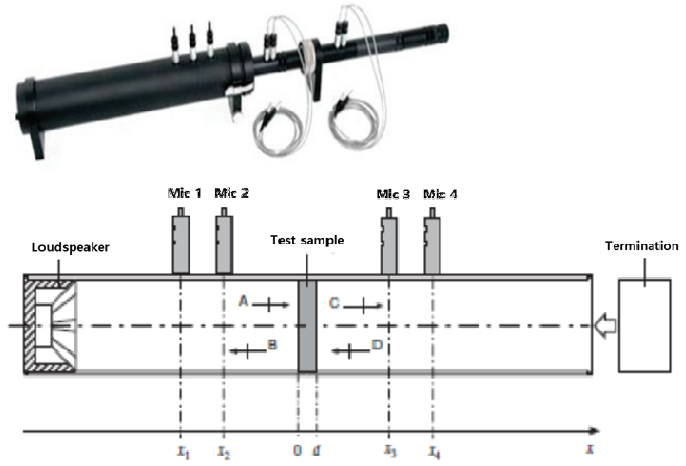

Fig. 2. Impedance tube for measuring sound transmission loss (top, photograph; bottom, schematic diagram). 
parts, as shown in Fig. 2. Four microphones were installed-two microphones on each side of the impedance tube. The sound transmission loss ratio was calculated from the transfer functions obtained from each of the microphones. The diameter of the impedance tube was $29 \mathrm{~mm}$; the frequency band used during the measurement was 500-6400 $\mathrm{Hz}$. The temperature and atmospheric pressure were $23^{\circ} \mathrm{C}$ and $1013.5 \mathrm{hPa}$, respectively.

\subsection{Measuring the transmission coefficient using the reverberation method}

Following the specified laboratory measurement method for the sound insulation performance of buildings (KS F ISO 10140-2:2010), a specimen was placed between the sound source room and the sound-receiving room, as shown in Figs. 3 and 4. The insulation performance was evaluated by measuring the differences in the sound pressure level. The sound barrier was installed between the sound source room (volume, $51.54 \mathrm{~m}^{3}$ ) and the sound-receiving room (volume, $57.02 \mathrm{~m}^{3}$ ). The sound pressure was measured by using five microphones installed each room. Further, 5.5 pieces of unit test specimens (width, $505 \mathrm{~mm}$; length, $3605 \mathrm{~mm}$; thickness, $95 \mathrm{~mm}$ ) were connected between the sound source room and receiving room. A specimen of length $3620 \mathrm{~mm}$ and height $2780 \mathrm{~mm}$ was installed, and the gap between the two boards was sealed using a sealant. During the measurement, the temperature, relative humidity, and atmospheric pressure were $7 \pm$ $1{ }^{\circ} \mathrm{C}, 41 \% \pm 3 \%$, and $100.9 \pm 0.1 \mathrm{kPa}$, respectively. The pure tone inside the sound source room was produced by a power amplifier (CONA V2-5000, Inter-M, Korea) and a loud speaker (D012, FALM, Germany/SRX 725, JBL, USA). The acoustical attenuation constant of specimens was calculated after measuring the average sound pressure level difference in two rooms using a real-time analyzer (PAK MK II MOLLER-BBM, Germany) and a $1 / 2$ " condenser microphone set (46AF, G.R.A.S., Denmark) in the sound-receiving room. As seen in Fig. 4, five omnidirectional microphones were set in each room at intervals of $0.7 \mathrm{~m}$. The microphones were installed $1.0 \mathrm{~m}$ from the sound resource and $0.7 \mathrm{~m}$ from the boundary of room and sound diffuser. The average energy value of the measured sound pressure level difference $(L)$ was calculated using Equation (1).

$$
L=10 \log \left(\frac{1}{n} \sum_{i=1}^{n} 10^{L_{i} / 10}\right)
$$
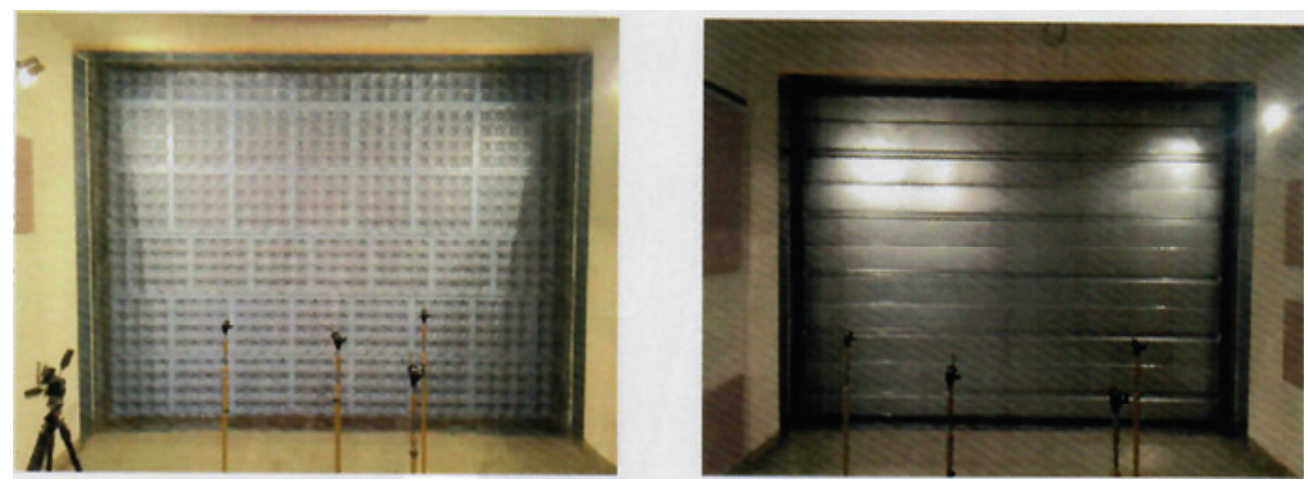

Fig. 3. Photographs of the measurement set up for the transmission coefficient (left: sound source room; right, sound-receiving room). 


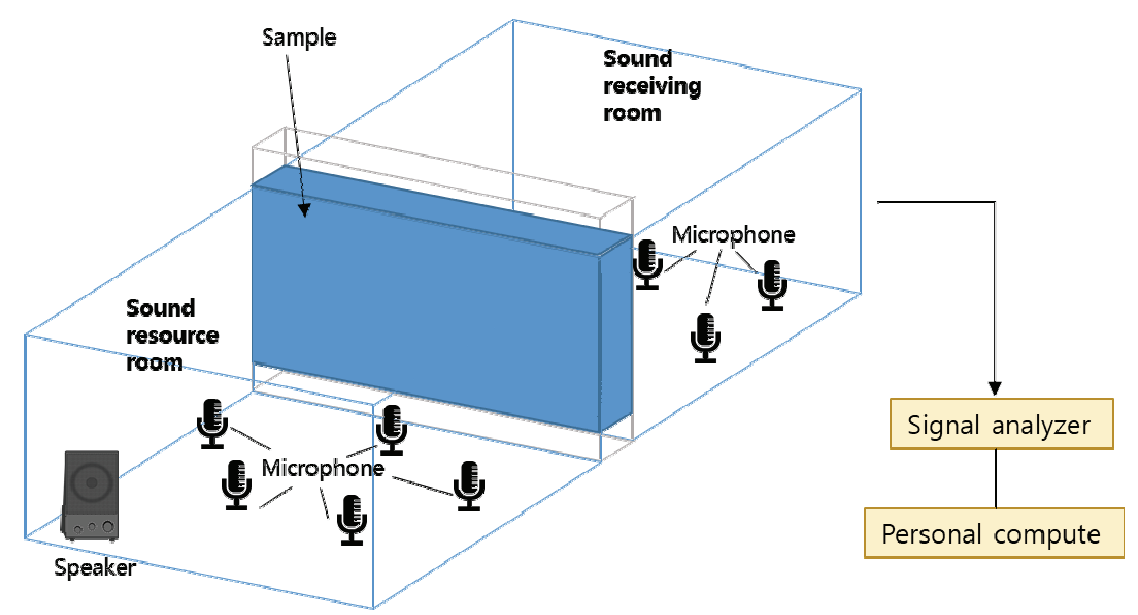

Fig. 4. Schematic of the laboratory measurement of the sound insulation performance of a building.

where $L_{\mathrm{i}}$ is the sound pressure level from fixed measuring point $\mathrm{I}(\mathrm{dB})$ and $n$ is the number of fixed measuring points.

Equivalent sound-absorbing power $A$ was calculated using Equation (2).

$$
A=\frac{0.16 V}{T}
$$

where $A$ is the equivalent sound-absorbing power $\left(\mathrm{m}^{2}\right)$, $V$ is the volume of sound-receiving room $\left(\mathrm{m}^{3}\right)$, and $T$ is the reverberation time of the sound-receiving room (s).

The acoustical attenuation constant $R$ was calculated using Equation (3).

$$
R=L_{1}-L_{2}+10 \log \left(\frac{S}{A}\right)
$$

where $L_{1}$ is the average sound pressure level of the sound source room $(\mathrm{dB}), L_{2}$ is the average sound pressure level of the sound-receiving room $(\mathrm{dB}), S$ is the area of the specimen $\left(\mathrm{m}^{2}\right)$, and $A$ is the soundabsorbing power of the sound-receiving room $\left(\mathrm{m}^{2}\right)$.

\section{RESULTS and DISCUSSION}

\subsection{Sound transmission loss measured by the transfer function method}

The transmission loss of specimens changed with the apparent specific density, as shown in Figs. 5-8.

During sound transmission loss measurement, the diameter of the impedance tube was limited by frequency: the diameter was $29 \mathrm{~mm}$ for the highfrequency range and $99 \mathrm{~mm}$ for the low-frequency range. In this study, the sound transmission loss was measured in the frequency range of $500-6.4 \mathrm{kHz}$ using the impedance tube of diameter $29 \mathrm{~mm}$.

The transmission loss of the rice-straw mat increased as the density increased and as the frequency increased. The transmission loss of the 50-mm-thick rice-straw mat with a density of $0.07 \mathrm{~g} / \mathrm{cm}^{3}$ was less than $5 \mathrm{~dB}$ for frequencies less than $1000 \mathrm{~Hz}$. Hence, such mats are not suitable as sound insulation materials; however, for frequencies greater than $1000 \mathrm{~Hz}$, the loss was 6-7 $\mathrm{dB}$. Further, in the frequency range of $3000-5000 \mathrm{~Hz}$, the loss was $25 \mathrm{~dB}$. The transmission loss of the 


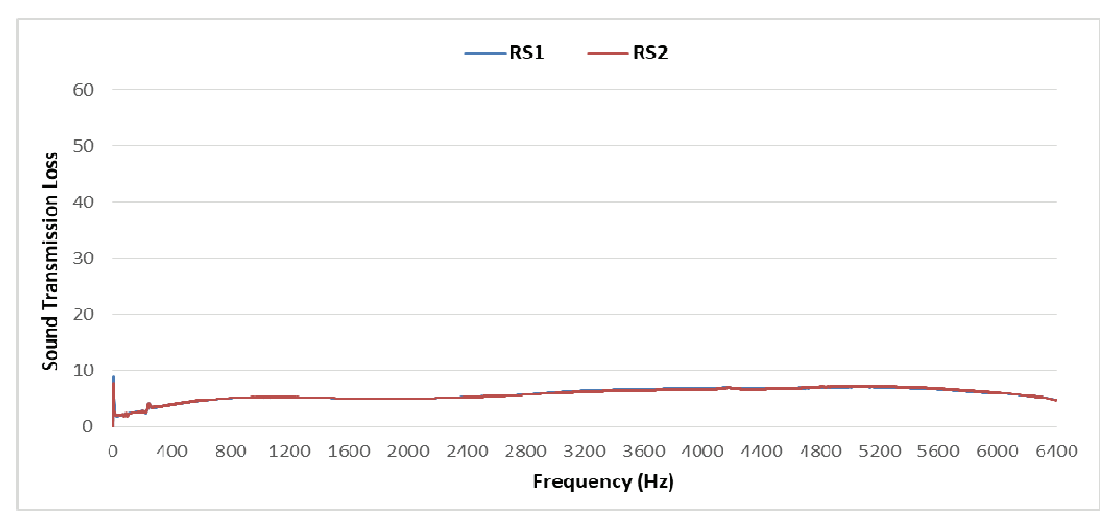

Fig. 5. Transmission loss of the rice-straw mat of thickness $5 \mathrm{~mm}$ and apparent specific density $0.07 \mathrm{~g} / \mathrm{cm}^{3}$.

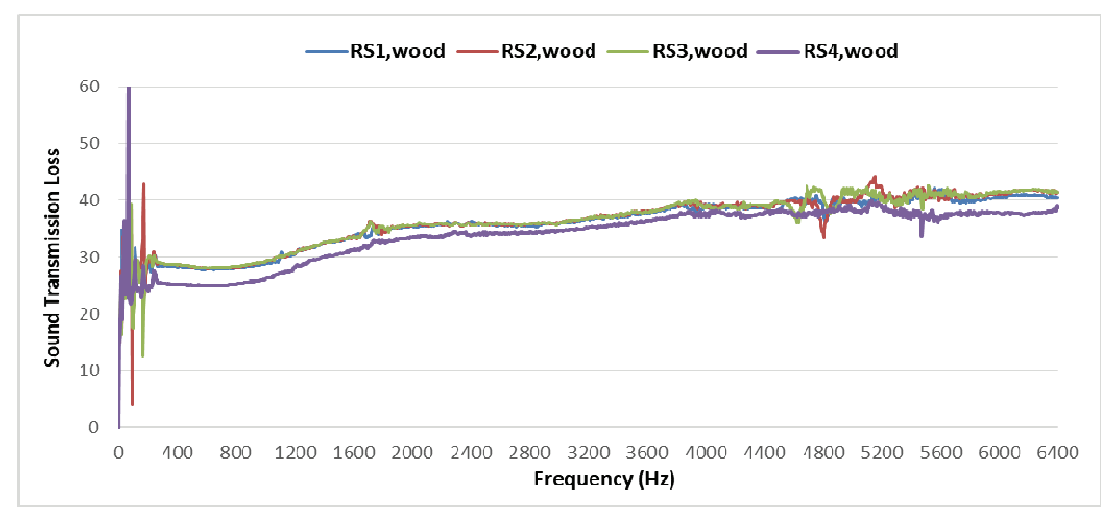

Fig. 6. Transmission loss of the rice-straw mat of thickness $5 \mathrm{~mm}$ and apparent specific density $0.07 \mathrm{~g} / \mathrm{cm}^{3}$ along with a 1-cm-thick plywood layer.

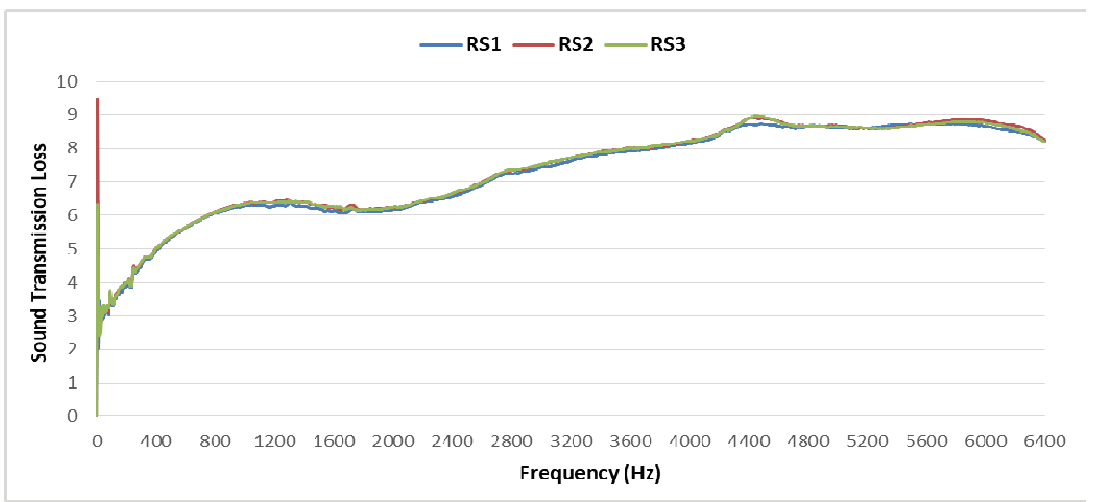

Fig. 7. Transmission loss of the rice-straw mat of thickness $5 \mathrm{~mm}$ and apparent specific density $0.12 \mathrm{~g} / \mathrm{cm}^{3}$. 
Measurement of Sound Transmission Loss in a Sound Barrier Filled with the Rice-Straw Particles by the Transfer Function and Laboratory Measurement Methods

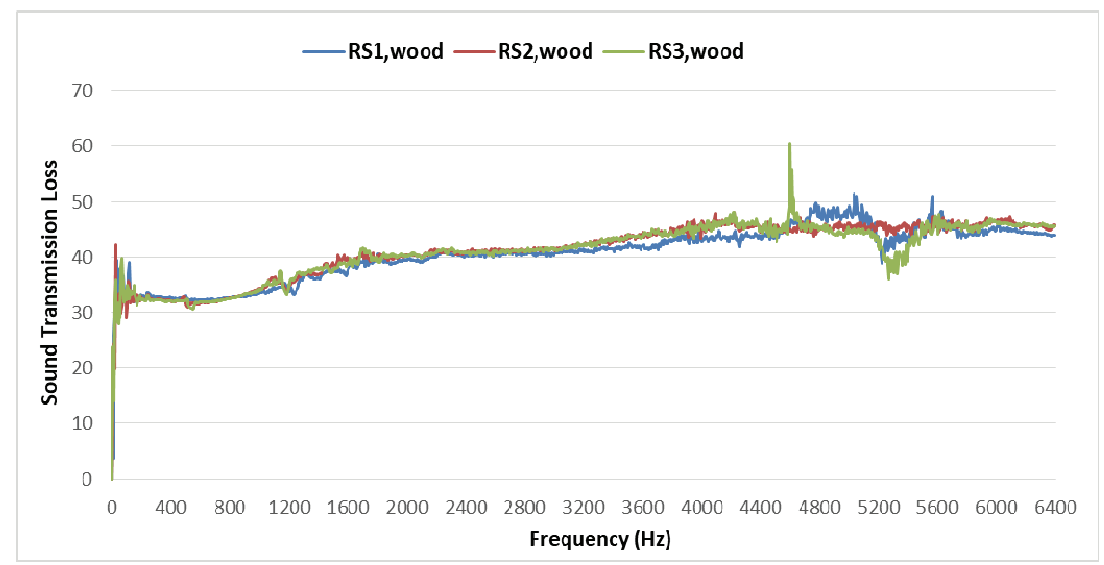

Fig. 8. Transmission loss of the rice-straw mat of thickness $5 \mathrm{~mm}$ and apparent specific density $0.12 \mathrm{~g} / \mathrm{cm}^{3}$ along with a 1-cm-thick plywood layer.

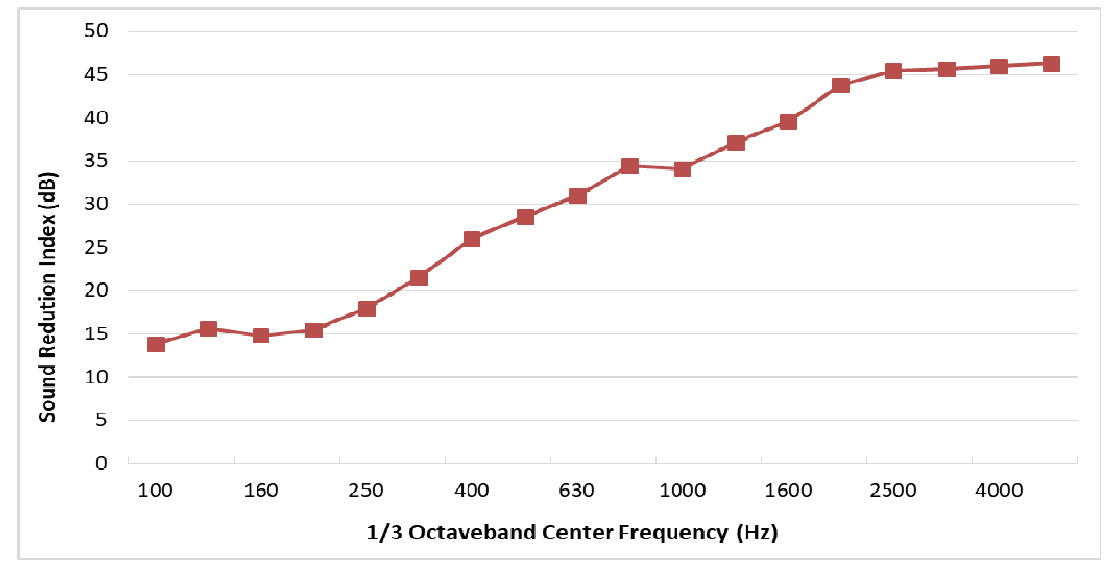

Fig. 9. Sound transmission loss by a laboratory measurement method.

50-mm-thick rice-straw mat with an additional 1-cmthick plywood layer was $25-28 \mathrm{~dB}$ at frequencies less than $1000 \mathrm{~Hz}$, greater than $30 \mathrm{~dB}$ for frequencies greater than $1000 \mathrm{~Hz}$, and 35-50 dB for the frequency range of 3000-5000 Hz. The 1-cm-thick plywood layer behaved as a 1-mm-thick iron back plate of the sound barrier owing to the similar surface density of the two layers. Such mats can be used as sound insulation materials.

\subsection{Sound transmission loss measured by the laboratory measurement method for sound insulation performance}

The sound transmission loss was also estimated by a laboratory measurement method. The results were directly compared with those obtained using the impedance tube method because both results were corrected by the environmental conditions. In the 
laboratory measurement method, the sound insulation performance of the building was obtained using five microphones installed at intervals of $0.7 \mathrm{~m}$ apart. The results are presented in Fig. 9. The transmission loss coefficient was $15 \mathrm{~dB}$ for frequencies less than 200 $\mathrm{Hz}, 35 \mathrm{~dB}$ for frequencies up to $800 \mathrm{~Hz}$, and $45 \mathrm{~dB}$ for a frequency of $2500 \mathrm{~Hz}$. According to the regulation of the Ministry of Land in Korea, the transmission loss coefficient of the sound barrier for roads should exceed $25 \mathrm{~dB}$ for a frequency of $500 \mathrm{~Hz}$ and $30 \mathrm{~dB}$ for a frequency of $1000 \mathrm{~Hz}$; in this study, the corresponding values of the sound barrier were $28.55 \mathrm{~dB}$ for $500 \mathrm{~Hz}$ and $34.1 \mathrm{~dB}$ for $1000 \mathrm{~Hz}$. The transmission loss of the specimens was close to but higher than the loss measured by the transfer function method for the frequency range $500-4000 \mathrm{~Hz}$. This could be attributed to the differences in the materials on which the sound is incident.

\section{CONCLUSION}

The sound transmission loss, which indicates the sound insulation capability of a building, was measured for a rice-straw particle mat by using the transfer function method and a laboratory measurement method. The measurement results were compared. The following conclusions were drawn.

1. The transmission loss values of the sound barrier filled with rice-straw particles as measured by the two methods were similar for $500-4000 \mathrm{~Hz}$.

2. The transmission loss of the sound barrier filled with rice-straw particle with an additional plywood layer was significantly higher; therefore, such mats are suitable for use as sound barriers for roads.

\section{ACKNOWLEDGMENT}

This study was carried out with the support of 'R\&D Program for Forest Science Technology
(Project No. "2017050C10-1719-BB02)' provided by Korea Forest Service (Korea Forestry Promotion Institute). And, authors thanks to the Seongwon safety construction company for their specimen preparation.

\section{REFERENCES}

ASTM E2611-09 Standard test method for measurement of normal incidence sound transmission of acoustical materials based on the transfer matrix method.

Kang, C.-W., Lee, Y.-H., Kang, H.-Y., Kang, W., Xu, H.-R., Chung, W.-Y. 2011. Radial variation of sound absorption capability in the cross sectional surface of yellow poplar wood. Journal of the Korean Wood Science and Technology 39(4): 326-332.

Kang, C.-W., Choi, I.-G., Gwak, K.-S., Yeo, H., Lee, N.-H., Kang, H.-Y. 2012. Changes of sound absorption capability of wood by Organosolv pretreatment. Journal of the Korean Wood Science and Technology 40(4): 237-243.

Kang, C.-W., Oh, S.-W., Lee, T.-B., Kang, W., Matsumura, J. 2012. Sound absorption capability and mechanical properties of a composite rice hull and sawdust board. Journal of Wood Science 8: 273-278.

Kang, C.-W., Park, H.-J., Jeon, S.-S. 2012. Sound absorption capability and bending strength of Miscanthus particle based board. Journal of the Korean Wood Science and Technology 40(1): 38-43.

Kang, C.-W., Jin, T, Kang, H.-Y. 2015. Effect of Flame Resistant Treatment on The Sound Absorption Capability of Sawdust-mandarin Peel Composite Particleboard. Journal of the Korean Wood Science and Technology 43(4): 511-517.

Kang, C.-W., Lee, C., Jang, E.-S., Jang, S.-S., Kang, 
Measurement of Sound Transmission Loss in a Sound Barrier Filled with the Rice-Straw Particles by the Transfer Function and Laboratory Measurement Methods

H.-Y. 2018. Changes in sound absorption capability and air permeability of Malas (Homalium foetidum) specimens after high temperature heat treatment. Journal of the Korean Wood Science and Technology 46(2): 149-154.

Kim, C.-W., Chang, T.-C., Kim, D.-S. 2012. Characteristics analysis of highway traffic noise. Transactions of the Korean Society of Noise and Vibration Engineering 22(12): 1191-1198.

Kim, D.-R., Kim, T.-M., Kim, J.-T., Park, G.-H., Ryu, L.-O. 2015. A Study on sensitivity of transmission loss using scaled reverberation chamber. Transactions of the Korean Society of Noise and Vibration Engineering 2015.4: 937-943.

Kim, J.-S. 2007. Characteristics of sound from construction equipment machinery room International Journal of Air-Conditioning and Refrigeration 36(1): 19-25.
Kook, J.-H., Jung, C.-W., Yun, J.-H., Kim, J.-S. 2007. Experimental study on wall sound transmission loss at construction equipment machinery room. Transactions of the Korean Society of Noise and Vibration Engineering 2007.3: 695-699.

Lee, J.-H., Kim, B.-S., Kim, K.-J. 2011. Study of sound transmission characteristics of using a scale reverberation chamber and vibro acoustic FEM. Transactions of the Korean Society of Noise and Vibration Engineering 2011.10: 92-95.

Hwang, S.-M., Kim, J.-D., Kwon, H., Seo, Y.-S. 2013. Sound transmission loss through double walls. International journal of naval architecture and ocean engineering 50(2): 64-68.

KS F ISO 10140-2 (2010) Acoustics--Laboratory measurement of sound insulation of building elements -- Part 2: Measurement of airborne sound insulation. 